\title{
O GÊNERO DA "NOVA CIDADANIA": O PROGRAMA MULHERES DA PAZ
}

\section{INTRODUÇÃO}

Desde 1990, observa-se uma acelerada mudança no modelo de políticas públicas que se consolidou nos anos pós-1945. A revalorização das políticas sociais, principalmente as de combate à pobreza e vulnerabilidade social, após uma década de crise e de liberalização da economia, fez emergir um novo paradigma institucional de políticas públicas, nomeado de diferentes maneiras, como pós-Consenso de Washington (Fine et al., 2001) cidadão-consumidor (Schild, 2007) ou investimento social (Jenson, 2009).

Particularmente, a distribuição de responsabilidades pelo bem-estar dos cidadãos entre Estado, mercado, comunidade e família sofreu uma significativa alteração que resultou no aumento do papel desempenhado por essas três últimas instituições e na redefinição do padrão de atuação do Estado. O controle direto pelo Estado da implementação de políticas públicas foi, crescentemente, cedendo lugar a diferentes formas de parcerias e de divisão de responsabilidades com organizações não governamentais (ONGs), igrejas, comunidades e com os beneficiários individualmente.

Além de mudanças institucionais, esse modelo introduziu uma nova noção de temporalidade nas políticas sociais (Olk, 2006). Como o próprio termo "investimento social" sugere, é o bem-estar futuro, mais do que o presente, o que define os resultados que se pretende alcançar. Enquanto na arquitetura do estado de bem-estar social anterior o foco se concentrava no provedor masculino e nos riscos inerentes ao mercado de trabalho, como o desemprego e os seus efeitos sobre o bem-estar da família, atualmente são as crianças e jovens que passaram a ter prioridade nas políticas sociais. Noções como o desenvolvimento de "capital humano" ou de "capacidades" dos beneficiários são consideradas ferramentas fundamentais para o novo modelo de cidadania que se pretende ativar, fundada nos valores de corresponsabilidade e independência face ao mercado e aos próprios programas sociais e assistenciais.

Indiscutivelmente, cada realidade nacional apresenta configurações específicas desse padrão emergente. No Brasil, tal modelo de política pública 
vem, crescentemente, se impondo e é notável a centralidade estratégica atribuída às mulheres na sua implementação, seja como clientes preferenciais de programas de combate intergeracional da pobreza, tal como nos programas de transferência de renda (Molyneux, 2006; Sorj \& Fontes, 2007; Suárez \& Libardoni, 2007), ou como operadoras, em nível local, de programas governamentais para a população considerada mais vulnerável.

O objetivo deste artigo é discutir as tensões geradas na concepção e implementação desse modelo de política social, na medida em que se ampliam consideravelmente os atores políticos nela envolvidos, em disputa. O Programa Mulheres da Paz (MP) servirá de referência empírica das considerações aqui realizadas.

O MP é um programa vinculado ao Ministério da Justiça e atua nos chamados "territórios vulneráveis", objetivando prevenir a entrada de jovens na criminalidade. Como veremos, o MP expressa a tensa convivência entre diferentes discursos e práticas que, ao mesmo tempo, mobilizam noções e pressupostos maternalistas, associados à feminilidade e colocados a serviço dos objetivos da política social, e novos conceitos de "cidadania ativa", que se baseiam na ideia de investir nos sujeitos como indivíduos e na valorização da autonomia e do autodesenvolvimento, o chamado empoderamento.

\section{POLÍTICAS SOCIAIS E “REFORMA DA SUBJETIVIDADE”}

A emergência de um novo paradigma de políticas sociais, que implicou a redefinição da relação entre Estado e sociedade e a promoção de novos comportamentos nos beneficiários, estimulou muitos analistas a buscarem um instrumental analítico que desse conta da mudança não apenas da prática das políticas sociais, mas da própria concepção do que se entende por cidadania (McKee, 2009).

Inspirados no conceito de governamentalidade de Foucault (2003), ${ }^{1}$ particularmente na importância que este autor confere às relações entre a institucionalização de um tipo de Estado e as formas de subjetivação a ele associada, a análise se deslocou do exame da racionalidade das políticas públicas, a partir da sua relação com metas definidas ou almejadas, para focar as políticas sociais como projetos morais e políticos, constituídos de discursos e práticas que transformam e regulam a conduta humana e produzem subjetividades (Larner, 2000). Trabalhando com problemática semelhante à de Norbert Elias (1994), que aponta para o longo processo de coevolução do Estado moderno e da moderna subjetividade, Foucault sugere, com o conceito de governamentalidade, a presença de uma racionalidade política que vai mais além das formas de gestão ou coordenação de diferentes instituições e atores reconhecidos pelo Estado, tal como propõe o conceito de governance. O conceito de governamentalidade indica que o governo está ativamente envolvido na produção de atores, 
de identidades e interesses, não apenas na sua coordenação. Visto por este ângulo, que poderíamos denominar o da política das políticas sociais, a análise envolve se interrogar sobre quais identidades são incentivadas, modificadas ou suprimidas pela ação dos programas sociais.

O conceito de governamentalidade, embora pouco desenvolvido, vem sendo utilizado para analisar as novas racionalidades e tecnologias políticas governamentais que marcam a transição do estado de bem-estar social de tipo keynesiano para o chamado neoliberal, ou mais recentemente, como decorrência de um esforço de recomposição do papel ativo do Estado, denominado de "investimento social". Na medida em que novas concepções de cidadania estão sendo introduzidas, às quais correspondem a produção de disposições de agir de modo "responsável" e "autônomo" por parte dos cidadãos, tal conceito tem sido muito recorrente entre os analistas do campo de estudos de políticas sociais.

Todavia, o conceito de governamentalidade, como alguns autores sugerem (Brockling et al., 2010), apresenta inúmeros desafios. Alguns deles se referem à ênfase excessiva conferida à análise dos princípios que sustentam a racionalidade de um modo de governar e que, em geral, se baseia na interpretação de documentos e discursos. O efeito disso é um estudo das mentalidades governantes desencarnadas de relações sociais ou, dito de outra forma, da percepção da realidade social como sendo uma derivação direta das mentalidades, conhecimentos e discursos dominantes. Como veremos, a nova arquitetura do estado de bem-estar social, que reúne uma grande diversidade de atores corresponsáveis pela sua concepção e implementação, é um campo de disputas e conflitos, de modo que o discurso sobre a "cidadania ativa" não pode ser tomado como um texto acabado, coerente e homogêneo; pelo contrário, ele é contingente e resulta das interações dos atores. Ademais, ocorrem importantes descontinuidades entre discurso e práticas sociais, potencializando a emergência de consequências não intencionais derivadas da relação entre os princípios políticos que regem o programa e o universo normativo local com o qual interagem. Desse modo, o conceito de governamentalidade na análise das políticas públicas deveria abranger a experiência, o modo de existência, dos embates entre diferentes racionalidades e orientações normativas, tanto daqueles qualificados como operadores políticos como daqueles identificados como seus beneficiários.

\section{GÊNERO E DESENVOLVIMENTO SOCIAL}

A emergência do novo paradigma de políticas sociais está ligada à ação de instituições muito influentes do sistema econômico internacional, como o Banco Mundial, que diagnosticaram, no decorrer da crise dos anos 80 , que o Estado, e mesmo o mercado, não poderiam ou não deveriam garantir sozinhos 
o bem-estar das pessoas. A nova agenda de desenvolvimento, preconizada pelas agências internacionais, recomendou o remodelamento da sua relação com os países clientes e desses com a "sociedade civil" sob a rubrica de "participação" e "empoderamento".

Além da adesão a uma concepção de desenvolvimento mais participativa, a fase "pós-consenso de Washington" representou um verdadeiro cultural turn [virada cultural] no Banco Mundial, que passou a se interessar pelo modo como os fatores culturais influenciam o processo de desenvolvimento (Rao \& Walton, 2004). Atribuindo o fracasso de muitos projetos de desenvolvimento ao desconhecimento das necessidades específicas das populações locais, o Banco Mundial abraça entusiasticamente a ideia de que crenças e valores deveriam ser levados em conta, inclusive como forma de ganhar o apoio das comunidades nas quais incidiriam os programas sociais.

As "organizações da sociedade civil" foram identificadas como cruciais para contribuir na melhoria da performance dos programas. Consideradas como instituições intermediárias entre os governos e os indivíduos, mais conectadas às realidades locais e mais eficientes para canalizar os esforços e os recursos para o desenvolvimento do que o corpo administrativo estatal, as ONGs são integradas como atores políticos centrais no processo de desenvolvimento. Sua participação nos programas sociais alcança o estatuto de uma diretriz prescrita aos países clientes.

Por razões diversas, o chamamento dos organismos internacionais e dos governos nacionais à integração de organizações não governamentais na concepção e implementação de políticas sociais coincide com uma mudança na orientação das ONGs, notadamente nos anos 1990. O ativismo apenas reivindicativo, característico dos anos 1980, parecia ter se esgotado, bem como as possibilidades de financiamento oriundo de agências externas. Inspirados por noções de democracia participativa, que valorizam a descentralização e o fortalecimento de laços comunitários, as ONGs estabelecem parcerias com o Estado na provisão de serviços para a população carente.

A participação de novos atores nos programas sociais introduz novas dinâmicas, fazendo-os oscilar entre diversas concepções e identidades de gênero. Por um lado, a valorização da "cultura familiar" local, isto é, o fortalecimento do modelo de família tradicional, a ser respeitado e reconhecido como uma base para a construção das redes de segurança para a população pobre (Bedford, 2009). A transferência de recursos para as mulheres é vista como trazendo melhores retornos ao desenvolvimento, o que é justificado pela percepção que associa mulheres, maternidade e cuidado. Nesse contexto, a valorização dos atributos femininos tradicionais é um "capital" a ser colocado a serviço dos programas de combate à pobreza e vulnerabilidade social. Por outro lado, e por influências de ONGs feministas, o Banco Mundial adota uma estratégia de promoção da igualdade de gênero no espaço doméstico e público como condição para a redu- 
ção da pobreza. ${ }^{2}$ Gerando dados globais, que estabelecem uma relação positiva entre mais igualdade de gênero e menor índice de pobreza, muitas demandas feministas passaram a integrar os indicadores de desenvolvimento. Todavia, essas duas perspectivas, a que valoriza as capacidades tradicionalmente associadas ao feminino e a perspectiva da igualdade de gênero estão em disputa nas políticas de desenvolvimento social nas últimas décadas.

\section{MULHERES DA PAZ E AS FEMINILIDADES EM DISPUTA}

O Programa Mulheres da Paz foi criado como parte de um programa mais abrangente, o Pronasci (Programa Nacional de Segurança com Cidadania), que é coordenado pelo Ministério da Justiça e se destina a articular ações estratégicas de ordenamento social e de segurança pública com políticas "sociais" e "preventivas", no intuito de atuar nas "raízes socioculturais" da criminalidade. Um dos principais públicos-alvo do Pronasci são jovens de 15 a 24 anos "à beira da criminalidade, que se encontram ou já estiveram em conflito com a lei" (Ministério da Justiça do Brasil, 2010).

Os estados e municípios têm autonomia para administrar e desenhar os instrumentos do Programa Mulheres da Paz. No Rio de Janeiro, o Mulheres da Paz está vinculado ao "Programa Protejo", cujo foco é "a formação da cidadania" de jovens expostos à violência doméstica ou urbana, por meio de programas de formação, inclusão social, atividades culturais e esportivas, que visem a "resgatar sua autoestima e permitir que eles disseminem uma cultura de paz em suas comunidades" (Ministério da Justiça do Brasil, 2007). São as Mulheres da Paz que identificam esses jovens, encaminham-nos ao Programa Protejo e "acompanham sua trajetória", "aconselhando-os e orientando-os". Os jovens e mulheres selecionados recebem uma bolsa mensal no valor de $\mathrm{R} \$ 100$ e $\mathrm{R} \$ 190$, respectivamente.

Diferentes discursos sobre a valorização das mulheres como agentes políticos da mudança co-habitam o universo programático das políticas sociais contemporâneas no Brasil e, em particular, do Programa Mulheres da Paz (MP). Comunicam percepções de gênero distintas que, no jogo administrativo das políticas, adquirem variadas configurações: oposição, disputa, aliança, acomodação.

Em seu desenho inicial, o Programa MP se identificava com o ideário de "Mães da Paz", muito forte no Estado Rio de Janeiro em virtude da visibilidade alcançada há alguns anos pelas organizações de mães que perderam seus filhos nos conflitos urbanos, notadamente, assassinados pela polícia. A mais conhecida dessas organizações no país, as Mães de Acari, teve origem quando um grupo de onze mulheres deu início a uma longa luta pela localização dos corpos de seus filhos e filhas, assassinados de uma só vez pela polícia no Rio de Janeiro, em julho de 1990. Transformando o luto materno em estratégia política, as 
Mães de Acari e outras organizações de mães tentam não apenas resolver seus casos pessoais, investigando e pressionando as autoridades, como também promover políticas públicas e medidas legislativas.

A articulação entre maternidade e política promovida pelos movimentos de mães ajuda a consolidar uma percepção que equaciona mulheres, maternidade e não violência. Por causa de sua experiência real ou virtual de maternidade, as mulheres percebem-se e são percebidas como mais cuidadosas e pacifistas. Baseados nesse pressuposto naturalizante de gênero, atores governamentais, não governamentais e movimentos populares do país promovem diversas iniciativas que buscam mobilizar as mulheres para campanhas de desarmamento, paz e prevenção à violência (Holzmann, 2006). O Programa MP foi originalmente inspirado pela ideia de institucionalizar os movimentos de mães, engajando-os em políticas de combate à criminalidade e promoção de uma "cultura de paz", por meio do diálogo com outras mães e ações de prevenção à entrada de jovens no crime organizado.

Ao longo de um processo disputado de articulações políticas, o projeto ganhou outras estruturas e conotações, que giram em torno da tensão mães versus mulheres. A Secretaria Nacional de Políticas para Mulheres (SPM), a partir de um viés feminista, identificou que o projeto, configurado como estava para promover a ação das mães junto aos jovens, tinha como pressuposto central a imagem e o papel de "mães/cuidadoras" das mulheres. A SPM posicionou-se contrariamente a isso e defendeu que o projeto deveria promover o "empoderamento" das mulheres, o que significaria "tirá-las do lugar de cuidadoras". A SPM sugeriu, então, que o programa deveria se chamar "Lideranças da Paz", o que, além de contemplar a meta de "empoderamento", admitiria também a possibilidade de inclusão de homens como operadores locais, enfraquecendo, assim, a associação entre o feminino e os cuidados. Este último ajuste não foi contemplado, e o programa ganhou o nome final de "Mulheres da Paz". ${ }^{3}$

A redação final do projeto, no artigo $8^{\circ}$ da Lei $n^{\circ} 11.707$, de 19 de junho de 2008 , mantém os objetivos originais e, ao mesmo tempo, incorpora algumas das mudanças sugeridas pela SPM. A tensão mãe versus mulher está inscrita no próprio texto legal:

O projeto Mulheres da Paz é destinado à capacitação de mulheres socialmente atuantes nas áreas geográficas abrangidas pelo Pronasci. O trabalho desenvolvido pelas Mulheres da Paz tem como foco:

I - a mobilização social para afirmação da cidadania, tendo em vista a emancipação das mulheres e prevenção e enfrentamento da violência contra as mulheres; e

II - a articulação com jovens e adolescentes, com vistas na sua participação e inclusão em programas sociais de promoção da cidadania e na rede de organizações parceiras capazes de responder de modo consistente e permanente às suas demandas por apoio psicológico, jurídico e social. (Brasil, 2008) 
O Rio de Janeiro foi pioneiro na implantação do Mulheres da Paz, capitaneada pela Secretaria Estadual de Assistência Social e Direitos Humanos do Rio de Janeiro (Seasdh) durante a gestão de Benedita da Silva, uma liderança política do Partido dos Trabalhadores, e vinculada à Igreja Evangélica. Em 2008, abriu-se um edital que selecionou 2.550 mulheres em dezoito territórios do estado identificados com "altas taxas de violência e criminalidade". As mulheres candidatas fizeram uma prova de seleção. Muitas delas já eram lideranças em suas comunidades, e foram indicadas por igrejas e associações de moradores.

A forte participação de mulheres ligadas à Igreja, notadamente as Evangélicas, se deve à sua expansão e revitalização nas comunidades populares do país, sobretudo por meio dos movimentos carismáticos e pentecostais. Revitalizaram-se também enquanto parceiras locais do Estado e de instituições de desenvolvimento, na provisão de serviços sociais. Pois como mostra Machado (1996), os movimentos pentecostais e carismáticos brasileiros fornecem instrumentos para um sentimento de dignificação e autoafirmação feminina que, certamente, se faz refletir na participação das mulheres nos assuntos das comunidades para além daqueles administrados pela Igreja. Nesse contexto, a legitimação da participação das mulheres como sujeitos políticos se dá a partir de seu papel de mães e principais cuidadoras da família; a busca por justiça e paz na comunidade, no espaço público, é um desdobramento do papel que lhes é atribuído no âmbito da família.

Todavia, a participação de organizações de direitos humanos e movimentos de mulheres no Programa MP, como em muitos projetos sociais na América Latina (Shild, 2007), introduz uma concepção de participação ancorada em outra chave política. Trata-se de valorizar a participação pública das mulheres pobres nas comunidades como forma de "empoderamento", como parte essencial de um projeto político de mudança das relações de gênero, que começa na transformação pessoal e se estende à família e ao ambiente em que atuam. Para tanto, educar as mulheres para temas como direitos, sexualidade e liderança comunitária, que as ajudem a superar formas opressivas de feminilidade e forjar novas subjetividades femininas, "modernas", constitui o fulcro dos cursos de capacitação oferecidos às Mulheres da Paz antes e durante sua atuação em campo. A metodologia da capacitação enfatiza metas como a valorização da autoestima e o autodesenvolvimento, ${ }^{4}$ enfim, uma "reforma da subjetividade".

\section{RECONSTRUÇÃO DO SELF E “EMPODERAMENTO”}

O empoderamento tornou-se a forma de subjetivação correspondente ao novo desenho das políticas sociais. Embora sua definição comporte vários significados em disputa, a ideia de que para mudar é necessário mudar o indivíduo, mediante uma tecnologia de intervenção, denominada, em geral, como capa- 
citação, representa uma ruptura com as perspectivas anteriormente prevalecentes que davam prioridade às transformações estruturais. A ênfase na "agência humana" ou no "protagonismo" como elo de conexão entre os níveis micro e macrossociais confere à atividade de capacitação/educação uma importância central no desenho do programa Mulheres da Paz.

As ONGs feministas e de direitos humanos integram o Programa MP na condição de especialistas em capacitação. O objetivo dos cursos, segundo uma coordenadora, seria "a mulher se reconhecer como pessoa partícipe da sua própria história e fazendo história”. Os cursos de formação foram, inicialmente, elaborados e oferecidos por uma empresa de consultoria, cuja equipe já havia participado de projetos feministas e da implantação de programas na área de prevenção em segurança pública do Pronasci, mais especificamente, na formação de policiais em "direitos humanos e cidadania".

Refletindo a trajetória política e profissional da consultoria, boa parte dos cursos oferecidos às mulheres abordava assuntos como "cidadania", "direitos humanos", "juventude" e "cultura de paz", e uma parte menor estava ligada ao chamado currículo feminista, com temas como "gênero", "violência contra a mulher" e "direitos sexuais e reprodutivos". ${ }^{5}$ Também foram promovidos encontros denominados "terapia comunitária", nos quais "a comunidade se trata".

Os cursos, ministrados por profissionais e professores ligados aos temas, articulavam aula expositiva e dinâmicas de grupo. A consultoria atribuía grande importância às dinâmicas, pois permitiam um modelo menos verticalizado de educação que valoriza a complementaridade entre o "saber especializado" e o "saber local". As dinâmicas compunham-se de jogos que buscavam estabelecer conexões entre os conteúdos da aula, o cotidiano local e a biografia das mulheres. Nessas atividades, as mulheres eram incentivadas a construir narrativas do self em que elas emergiam como indivíduos "empoderados", capazes de agência social e autotransformação. Isso fica evidente na ementa dos cursos, segundo a qual, no primeiro dia de formação, as mulheres eram convidadas a "valorizar seu papel enquanto atrizes/atoras sociais conscientes e engajadas, protagonistas da prevenção da violência e em busca de sua autonomia".

Os conteúdos de cidadania, direitos humanos, juventude e cultura de paz buscavam promover uma reflexão acerca da importância do diálogo, da tolerância e consciência da diversidade dos seres humanos nas relações sociais e com o Estado. O aprendizado desses valores, apresentados como condizentes com a democracia e com um paradigma de segurança pública que não está mais voltado apenas à repressão, mas principalmente à promoção da cidadania, é considerado essencial para capacitar as mulheres a agir em suas comunidades e com os jovens.

Os conteúdos ligados à questão de gênero buscavam conscientizar as participantes de que a cultura patriarcal estabelece comportamentos e posições de poder diferenciados para homens e mulheres. Resultantes de processos 
históricos e culturais, e não biologicamente determinados, esses padrões e desigualdades de gênero poderiam e deveriam ser questionados pelas mulheres, encorajando-as a ocupar espaços de liderança comunitária.

Mas também, e acima de tudo, a "consciência de gênero" é retraduzida nesses cursos pela gramática política da autoestima, da identidade e do corpo, que a situa e lhe confere sentido nos planos individual e psicológico. As ementas e práticas dos cursos estimulam a reflexão sobre a "inter-relação entre os valores sócio-culturais adquiridos sobre o 'ser mulher' e as trajetórias individuais", e "ponderar até que ponto os valores adquiridos, a sua aceitação ou questionamento, interferem na autoestima e no direcionamento da vida". Seu "corpo biológico" é diferenciado de seu "corpo simbólico", aquele que requer "autocuidado e autoestima". Elas são estimuladas a falar sobre seus "sentimentos" e "autoimagem" e identificar "o que deve ser preservado e o que pode ser transformado". ${ }^{6}$ O empoderamento das mulheres como cidadãs ativas é, assim, fundamentado na construção da autoestima do self feminino e na valorização da ação junto à comunidade.

Duas visões de empoderamento por vezes conflitam e, por vezes, aparecem como parte de um mesmo contínuo: o empoderamento individual das mulheres, que se traduz na busca de um investimento no seu próprio bem-estar, mais sintonizado com o componente feminista do Programa MP, e o empoderamento voltado para o bem-estar de outros, no caso o resgate dos jovens em situação de risco.

O empoderamento que resulta na autotransformação é, muitas vezes, assumido como um valor em si do programa, tanto para gestores como para operadoras e beneficiárias. Assim, mudanças individuais exemplares são recorrentemente acionadas como símbolo de sucesso do empoderamento visado pelo programa e são consideradas como bons argumentos para a manutenção do programa na comunidade. ${ }^{7}$ Ao mesmo tempo, esse empoderamento individual deve ser posto a serviço do cuidado com os jovens, que são o foco principal do programa. A passagem do nível do empoderamento individual para o empoderamento via comunidade, no qual elas desempenham o papel de cuidadoras dos jovens em situação de risco, é permeado por tensões.

Muitas mulheres se questionam se ao final da sua participação no programa suas vidas poderão melhorar e se orientam para construir, desde já, condições que viabilizem sua inserção no mercado de trabalho ou em atividades de geração de renda para si próprias. Acreditam que já aprenderam o suficiente sobre "direitos humanos e cidadania" e reclamam da inexistência de cursos de capacitação profissional que lhes abram novos horizontes ocupacionais, à semelhança do Programa Protejo, voltado à inserção dos jovens no mercado de trabalho. ${ }^{8}$ Segundo essas mulheres, ao mantê-las excluídas de formações profissionalizantes e do mercado de trabalho, o programa acaba servindo, nos termos delas, à "exploração", por parte do governo e de ONGs, 
que as utilizam como "porta de entrada" para a comunidade, aproveitando-se de seus "serviços e conhecimentos", sem, no entanto, "reconhecerem o [seu] trabalho" adequadamente. "Entregamos o mapa da mina ao PAC [Programa de Aceleração do Crescimento]", dizem algumas, "nos sentimos usadas". "A gente tem que estudar, para não ser apenas uma porta aberta para os outros", diz uma Mulher da Paz, para quem o estudo formal é a única chance de ingressar no mercado de trabalho. ${ }^{9}$ Principalmente, a valorização da participação no mercado de trabalho ou de geração de renda por meio de algum empreendimento parece resumir o momento considerado mais bem-sucedido do empoderamento. "A gente não pode ser cabide de bolsa do governo. Para pagar as contas e ter direitos de cidadão, tem que ter emprego. A bolsa satisfaz? A formação que recebemos é para a gente se conscientizar de que precisamos de emprego. Bolsa não é emprego", diz uma entrevistada, de cerca de 50 anos, que começou como Mulher da Paz, mais tarde foi promovida ao cargo de educadora do programa e passou a receber salário. Desafiando os limites do enquadramento das suas atividades pelo Programa, as mulheres deslocam sua ação para a promoção de novas oportunidades de inserção no espaço público e em atividades geradoras de renda. Assim, multiplicam-se formas de associativismo como a associação comunitária autônoma de mulheres, a rádio comunitária composta apenas por mulheres, cooperativas de artesanato para geração de renda. Algumas aspiram a tornar-se assalariadas em funções de serviços comunitários, como conselheiras tutelares ou conciliadoras populares em um centro de mediação de conflitos a ser instalado pelo governo. Além disso, pressionam os gestores governamentais do programa e outros atores políticos para criar políticas de inserção no mercado de trabalho, de educação formal e de capacitação profissional.

Para outras mulheres pertencentes ao MP, "cuidar de outros" e "cuidar de si" não é percebido como uma oposição. Investidas da autoridade do programa, a ação de cuidar dos jovens é muito valorizada e abre a oportunidade de ganharem reconhecimento e distinção na comunidade. Ganhar "respeito", "consideração" e "liderança" frente aos vizinhos e aos poderes locais são recompensas altamente valorizadas.

\section{O GÊNERO DO RISCO SOCIAL}

A existência de um discurso oficial, que propunha o empoderamento das mulheres nos termos das abordagens feministas e dos direitos humanos, e que se materializa na oferta de cursos de capacitação, ainda não garante que ele seja traduzido imediatamente nas práticas do programa. Não apenas porque, como vimos, o conceito de empoderamento tem muitos significados, mas porque ele convive com outras moralidades que produzem uma apropriação muito peculiar do discurso feminista e dos direitos humanos. Definir jovens em "situação de 
risco", que devem ser identificados pelas MP e encaminhados ao Protejo, aciona um conjunto de significados associados às distinções de gênero.

É bastante comum a adoção, pelas Mulheres da Paz, de uma visão ampliada de risco que abarcaria todos os jovens da comunidade. Pelo fato de terem contato com a "cultura do tráfico", ou simplesmente por serem pobres e marginalizados, seriam jovens potencialmente vulneráveis. Isso, segundo algumas entrevistadas, por si só justificaria a entrada de toda a população jovem da comunidade no Programa Protejo, com exceção dos jovens ligados às Igrejas Evangélicas. Estes últimos estariam protegidos dos desvios de conduta porque compartilham de uma comunidade diferenciada, que exerce forte controle sobre os comportamentos dos fiéis e que consegue contrapor à cultura do tráfico outra visão de mundo.

A noção ampla de risco é, em parte, fruto da própria falta de especificidade do edital do programa, segundo o qual "é perfil do público-alvo do Protejo o(a) jovem ou adolescente que estiver em situação de vulnerabilidade social, de risco ou de violência doméstica ou urbana". Mas, em parte, é também uma forma de as mulheres ampliarem seu poder de decisão sobre a seleção dos jovens, justificando, inclusive, que selecionem seus familiares. ${ }^{10}$

O gênero é um dispositivo que permite definir diferentes situações de risco. Enquanto o risco dos meninos é definido por sua proximidade com a cultura do tráfico (contato com amigos ou parentes traficantes, gostar de funk "proibidão"), o risco das meninas está ligado à forma de exercício de sua sexualidade.

Algumas adolescentes com vida sexual ativa fora de uma relação estável, são designadas pelas Mulheres da Paz como exercendo "prostituição simbólica". Assim se expressam duas mulheres em entrevista: ${ }^{11}$

- Tinha muitas jovens na condição de prostituição aqui, entendeu! Não por dinheiro, era um outro tipo de prostituição. Assim... elas não preservavam seu corpo, entendeu?

A segunda mulher intervém:

- A menina tem a questão [...] do corpo, da própria prostituição simbólica, que às vezes não ta ganhando nada, ela não ta ali fazendo programa, mas ela não se reconhece, não guarda o corpo, acha realmente comum. Por que é comum? Porque foi criada numa cultura da comunidade que, vamos pensar... uma menina hoje com 15, 16 anos, se ela for virgem... ela não é aceita no grupo.

A noção de risco feminino é inspirada pelo ideário de direitos humanos e do feminismo, pois se legitima pelo discurso da autonomia sobre o corpo, da sua "não-objetificação" sexual. Os significados morais que os atos sexuais fora da relação estável adquirem, se relacionam à condenação do sexismo entre as Mulheres da Paz.

As diferenças de gêneros continuam então a conformar o mapa moral que permite classificar diferentes situações de risco e a sexualidade feminina constitui o marcador mais importante de diferenciação do risco entre as jovens. 


\section{CONCLUSÕES}

O novo paradigma das políticas sociais repousa na ideia de um novo cidadão dotado de autonomia e responsabilidade pelo bem-estar da sua comunidade e de si mesmo. Todavia, como o novo paradigma supõe um modelo de corresponsabilidade entre diferentes atores institucionais, nem sempre com visões convergentes, e entre estes e as mulheres que operam o programa em nível local, a própria definição dos significados, objetivos e as maneiras das intervenções estão em constante disputa. De modo que, se o conceito de governamentalidade é muito interessante porque remete à importância da subjetivação para a realização do novo projeto de cidadania, a análise da atuação das mulheres na comunidade mostra que as políticas sociais não podem ser interpretadas como um texto e uma prática coerente e acabada.

Como vimos, desde a nomeação do Programa Mulheres da Paz, passando pelos cursos de capacitação, até a maneira como as mulheres redefinem os próprios objetivos do programa, o novo paradigma do "investimento social" é permeado por disputas entre diferentes interesses e conceituações que acarretam consequências não previstas. As Mulheres da Paz, em boa medida, redefinem os objetivos iniciais do programa, nem sempre confirmam o lugar de cuidadoras que lhes é atribuído; tentam caminhos alternativos para investir em si mesmas, trazendo para o presente os benefícios que o Programa Mulheres da Paz aspira alcançar apenas no futuro.

Artigo recebido para publicação em junho de 2011.

Bila Sorj é professora titular do Departamento de Sociologia da Universidade Federal do Rio de Janeiro (UFRJ) e pesquisadora do Conselho Nacional de Desenvolvimento Científico e Tecnológico (CNPq). Dedica-se ao estudo das desigualdades de gênero focando as seguintes temáticas: família, pobreza e políticas sociais. Recentemente co-organizou as coletâneas Mercado de trabalho e gênero (2008) e Gênero, violência e direitos humanos na sociedade brasileira (2009).

Carla de Castro Gomes é mestre em Sociologia pela Universidade Federal do Rio de Janeiro (UFRJ) e pesquisadora do Núcleo de Estudos de Sexualidade e Gênero, da mesma instituição. Estudou a aplicação da Lei Maria da Penha e publicou em coautoria o artigo "O caleidoscópio da 'violência conjugal': instituições, atores e políticas públicas no Rio de Janeiro" (2009). 


\section{NOTAS}

1 Para uma visão geral do conceito de governamentalidade em Foucault, ver Meyet, (2005) e Avelino (2010).

2 De acordo com o site do Banco Mundial, "World Bank attention to gender equality issues began in the 1970s, but the Bank's emphasis on this issue has increased markedly since the Fourth World Conference on Women held in Beijing in 1995. Gender equality is now a core element of the Bank's strategy to reduce poverty." Disponível em <http:// web.worldbank.org/WBSITE/EXTERNAL/TOPICS/EXTGEND ER/0,,contentMDK:20260262 menuPK:489120 pagePK:1489 56 piPK:216618 theSitePK:336868,00.html>. Acesso em 17 jun. 2011.

3 Estas e outras informações sobre o programa MP foram coligidas por meio de pesquisa documental e trabalho de campo, que incluiu, até o momento, 15 entrevistas formais (gravadas ou registradas por escrito) com gestores e mulheres que entraram no programa em 2008. Além disso, houve observação de diversas atividades, como reuniões entre mulheres e gestores, cursos de capacitação de mulheres, rotina de trabalho das mulheres com os jovens, eventos públicos (feira de economia solidária, da qual mulheres participaram como expositoras; lançamento de livro institucional sobre o programa; cerimônias institucionais e comemorações), entre outras ocasiões, em que foi possível conhecer e conversar informalmente com diversos atores. O trabalho de campo, ainda em curso, iniciou-se em setembro de 2010, por meio de encontro com a consultora responsável pelos cursos de capacitação das mulheres, que posteriormente facilitou nosso primeiro contato com gestores. Estes, por sua vez, franquearam nosso acesso a atividades e documentos relacionados ao programa e forneceram os contatos iniciais que nos permitiram entrar na rede de mulheres, coordenadores e educadores locais e outros participantes. Ocasionalmente, também tivemos contatos informais com feministas ligadas à SPM e aos movimentos de mulheres, que forneceram algumas informações sobre o processo de formulação do programa.

4 De acordo com relato da consultora dos cursos de capacitação, um dos antecedentes desta metodologia foram os 
grupos de reflexão, muito comuns nos anos de 1970, organizados por feministas, como modo de as mulheres ganharem conhecimento sobre sua opressão, partindo da análise das suas próprias vidas, sem a interferência da presença dos homens.

5 Os cursos oferecidos pela consultoria foram: Acolhimento e apresentação do Pronasci; Segurança pública cidadã; Cidadania; Direitos humanos e cultura de paz; Mediação e facilitação de diálogos e atividades colaborativas; Formação de redes sociais; Cidadania e arranjos familiares; Juventudes, como trabalhar com jovens do Protejo; Estatuto da Criança e do Adolescente; A sociedade e o uso de substâncias psicoativas; Educação socioambiental; Diversidades e desigualdades; Violências e suas manifestações; Violência contra a mulher e Lei Maria da Penha; Gênero e identidade feminina; e Direitos sexuais e reprodutivos.

6 Trechos das ementas dos cursos, fornecidas pela coordenação do programa.

7 Em entrevista, a coordenadora da consultoria destaca, com orgulho e emoção, o depoimento que lhe foi dado por uma Mulher da Paz, e que ilustra a centralidade das narrativas do self: "você não me tirou só do fogão, da minha casa; você me tirou da depressão". Em conversa informal conosco, outra Mulher da Paz (de cerca de 60 anos, casada, mãe de uma filha, empregada como acompanhante de idoso) protesta contra o fim do programa: "o encerramento do programa deveria ser feito assim: todas as mulheres deviam chegar lá e contar sua história de vida e sua história no programa", diz. Segundo ela, a "história" das mulheres no programa era reveladora de grandes transformações pessoais, que constituíam o principal feito do programa e justificavam a sua continuidade.

8 Essa reivindicação parece ser comum às mulheres que participam de programas sociais que têm como foco crianças e jovens e nos quais elas exercem algum papel maternalista (Molyneaux, 2006).

9 Senhora de cerca de 65 anos, pastora de igreja evangélica. 10 A seleção de jovens ligados às mulheres por laços de parentesco ocorreu, ao que tudo indica, em grandes proporções e motivou, posteriormente, mudanças no processo de seleção, que passou a contar com a participação de outros atores. 
11 A primeira delas é Mulher da Paz, tem cerca de 40 anos, casada, seis filhos, fundadora e eleita primeira presidente da Associação de Mulheres local, composta por Mulheres da Paz. A segunda interlocutora é a mesma que foi promovida ao cargo de educadora, citada anteriormente.

\section{REFERÊNCIAS BIBLIOGRÁFICAS}

Avelino, Nildo. Governamentalidade e anarqueologia em Michel Foucault. Revista Brasileira de Ciências Sociais, 2010, 25/74, p. 139-195.

Bedford, Kate. Gender and institutional strengthening: The World Bank's Policy Record in Latin America. Contemporary Politics, 2009,15/2, p. 197-214.

Brasil. Lei $\mathrm{n}^{\circ}$ 11.707, de 19 de junho de 2008. Altera a Lei $\mathrm{n}^{\circ}$ 11.530, de 24 de outubro de 2007, que institui o Programa Nacional de Segurança Pública com Cidadania - Pronasci. Disponível em <http://www.planalto.gov.br/ccivil_03/_ato20072010/2008/Lei/L11707.htm\#art2>. Acesso em 5 out. 2010.

Fundação Darcy Ribeiro. Edital n 08/2008. Seleção para preenchimento de vagas para as atividades do projeto PROTEJO, integrante do Programa Nacional de Segurança Pública com Cidadania - Pronasci. Disponível em <http://www. fundar.org.br/Edital\%20Protejo\%20pdf.pdf>. Acesso em 5 out. 2010.

Brockling, Urlich et al. Governmentality: current issues and future challenges. Londres: Routledge, 2010.

Elias, Norbert. O processo civilizador. Rio de Janeiro: Jorge Zahar, 1994 (2 vol.).

Fine, Ben et al. Development policy in the twenty-first century: beyond the post-Washington Consensus. Londres: Routledge, 2001.

Foucault, Michel. Governmentality. In: Rabinow, Paul \& Rose, Nikolas (orgs). The essencial Foucault: selections from essencial works of Foucault, 1954-1984. Londres: New Press, 2003, p. 229-245.

Holzmann, Nora. Missing men, waking women: a gender perspective on organised armed violence in Brazil. In: In- 
ternational Yearbook of Regional Human Rights Master's Programmes 2006. Cape Town: ABC Press, 2008. Disponível em <http://www.chr.up.ac.za/index.php/masters-llm-publications.html>. Acesso em 10 jun. 2011.

Jenson, Jane. Lost in translation: the social investment perspective and gender equality. Social Politics: International Studies in Gender, State and Society, 2009, 16/4, p. 446-83.

Larner, Wendy. Post-welfare state governance: towards a code of social and family responsibility. Social Politics: International Studies in Gender, State and Society, 2000, 7/2, p. 244-65. Machado, Maria das Dores Campos. Carismáticos e pentecostais: adesão religiosa na esfera familiar. Campinas: Ed. Autores Associados/Anpocs, 1996.

McKee, Kim. Post-Foucaultian governamentality: what does it offer critical social policy analysis? Critical Social Policy, 2009, 29/3, p. 465-486.

Meyet, Sylvain. Les trajectoires d'un texte: "La gouvernementalité" de Michel Foucault. In: ; Naves, Marie-Cécile \& Ribemont, Thomas (orgs). Travailler avec Foucault: retours sur le politique. Paris: L'Harmattan, 2005, p.13-36.

Ministério da Justiça do Brasil. O que é o Pronasci, 2010. Disponível em <http://portal.mj.gov.br/Pronasci/data/Pages/ MJE24DOEE7ITEMIDAF1131EAD238415B96108A0B8A0E7398PTBRIE.htm>. Acesso em 3 out. 2010.

. Integração do jovem e da família, 2007. Disponível em <http://portal.mj.gov.br/data/Pages/MJ3FD1029CITEMIDFA34A8C4A1F14C2BBECEDF60C7C0A2ACPTBRIE.htm>. Acesso em 3 out. 2010.

Molyneux, Maxine. Mothers at the Service of the new poverty agenda: progresa/oportunidades, Mexico's Conditional Transfer Programme. Social Politics and Administration, 2006, 40/4, p. 429-40.

Olk, Thomas. Children in the "Social Investment State". Trabalho apresentado no WELLCHI Network Conference 2, Centre for Globalisation and Governance, University of Hamburg, 2006.

Rao, Vijayendra \& Walton, Michael. Culture and public action. Palo Alto, CA: Stanford University Press, 2004.

Schild, Verónica. Empowering "consumer-citizens" or gov- 
erning poor female subjects? The institutionalization of "self-development" in the Chilean social policy field. Journal of Consumer Culture, 2007, 7, p. 179-203.

Sorj, Bila \& Fontes, Adriana. Políticas públicas e a articulação entre trabalho e família: comparações interregionais. Interseções, 2007, 2, p. 267-285.

Suárez, Mireya \& Libardoni, Marlene. O impacto do Programa Bolsa Família: mudanças e continuidades na condição social das mulheres. In: Vaitsman, Jeni \& Paes-Sousa, Rômulo. Avaliação de Políticas e Programas do MDS: Resultados. Brasília: MDS/SAGI, 2007, p. 119-160 (Vol. II: Bolsa Família e Assistência Social).

World Bank. Gender in the World Bank, 2007. Disponível em <http://web.worldbank.org/WBSITE/EXTERNAL/TOPICS/EX TGENDER/0,,contentMDK:20260262 menuPK:489120 page PK:148956 piPK:216618 theSitePK:336868,00.html>. Acesso em 13 jul. 2011. 


\section{Resumo:}

Este artigo discute o novo paradigma de políticas sociais, nomeado de diferentes maneiras, como pós-Consenso de Washington, cidadão-consumidor ou investimento social e as formas que assume no contexto brasileiro. Toma-se como referência empírica o Programa Mulheres da Paz, do Rio de Janeiro, que visa a capacitar mulheres de comunidades pobres a "resgatar" jovens em situação de risco e criminalidade e a atuarem como lideranças locais. O artigo analisa a tensa convivência entre diferentes discursos e práticas que, ao mesmo tempo, mobilizam pressupostos maternalistas, associados à feminilidade e colocados a serviço dos objetivos do desenvolvimento e os novos conceitos de "cidadania ativa", que se baseiam na ideia de investir nos sujeitos como indivíduos e na promoção da autonomia e do autodesenvolvimento, o chamado empoderamento.

\section{Abstract:}

This article discusses the new paradigm of social policies named post-Washington Consensus, citizen-consumer or social investment and the forms it assumes in the Brazilian context. The empirical reference is the Women for Peace Program in Rio de Janeiro which aims at empowering women in poor communities to "rescue" young people at risk of joining organized crime and to act as local leaders. The article analyzes the tense coexistence of different discourses that mobilize maternalist assumptions associated with femininity placing them at the service of development goals and the new concepts of "active citizenship", which are based on the idea of investing in the subjects as individuals and promoting autonomy and self-development, the so-called empowerment.
Palavras-chave:

Políticas sociais; Gênero; Empoderamento; Maternalismo; Mulheres da Paz.

\section{Keywords:}

Social politics; Gender; Empowerment; Maternalism; Mulheres da Paz. 